\title{
Trichrome Staining Method
}

National Cancer Institute

\section{Source}

National Cancer Institute. Trichrome Staining Method. NCI Thesaurus. Code C23012.

A histological staining method that uses acid dyes and washes to selectively dye the structural elements in tissue samples in three or more contrasting colors. 